\title{
Semillas de siratro (Macroptilium atropurpureum) sometidas a escarificación química y térmica
}

\section{Seeds of siratro (Macroptilium atropurpureum) brought under chemical and thermal scarification}

Francisco Javier Oñate Mancero. ${ }^{1}$, Orlando Bravo Calle. ${ }^{2}$, Enrique Vaca Zambrano. ${ }^{3} \&$ Santiago Toapanta Santacruz. ${ }^{4}$

Recibido: 21-04-2019 / Revisado: 28-05-2019 /Aceptado: 30-06-2019/ Publicado: 15-07-2019

\begin{abstract}
.
DOI: https://doi.org/10.33262/cienciadigital.v3i3.1.683

In general, Forage legumes represent a high protein value; however, they have limitations for their settlement owing to the latency of the seeds. Based on this, the germination of Macroptilium atropurpureum seed was evaluated, after receiving chemical scarification with $96 \%$ sulfuric acid in immersion for three minutes, immersion in hot water at $80^{\circ} \mathrm{C}$ for five minutes, in potable room temperature water for 24 hours and controlled seeds (untreated). The quantified variables were seed yield, germination, and survival of seedlings. We found 73,000 viable seeds and 3\% impurities for each kilogram of collected seed. The treated seeds with sulfuric acid were those that presented a better percentage of germination and survival (80 and $75.56 \%)$; followed by those treated with water at $80^{\circ} \mathrm{C}(75.56$ and $73.34 \%)$. The scarification of legume seeds should be an essential procedure using concentrated sulfuric acid since the best results were found in seed germination and seedling survival.
\end{abstract}

Keywords: Scarification, Dormancy, Germination, Legume, Siratro.

\footnotetext{
${ }^{1}$ Escuela Superior Politécnica de Chimborazo sede Morona Santiago. Grupo de Investigación para el Desarrollo Sustentable (GIDES), Macas, Ecuador, francisco.oniate@espoch.edu.ec

${ }^{2}$ Escuela Superior Politécnica de Chimborazo sede Morona Santiago. Grupo de Investigación para el Desarrollo Sustentable (GIDES), Macas, Ecuador, obravo@espoch.edu.ec

${ }^{3}$ Escuela Superior Politécnica de Chimborazo sede Morona Santiago. Grupo de Investigación para el Desarrollo Sustentable (GIDES), Macas, Ecuador, sevacaz@espoch.edu.ec

${ }^{4}$ Escuela Superior Politécnica de Chimborazo sede Morona Santiago. Carrera de Zootecnia. Macas, Ecuador, santiago.toapanta@espoch.edu.ec
} 


\section{Resumen.}

Las leguminosas forrajeras, en general representan alto valor proteico; sin embargo, presentan limitaciones para su establecimiento debido a la latencia de las semillas. En función de ello, se evaluó la germinación de la semilla de Macroptilium atropurpureum, luego de recibir escarificación química con ácido sulfúrico al 96\% en inmersión durante tres minutos, inmersión en agua caliente a $80^{\circ} \mathrm{C}$ durante cinco minutos, en agua potable al ambiente durante 24 horas y un testigo (sin tratar). Se aplicó un diseño completamente aleatorizado con 15 repeticiones cada uno. Las variables cuantificadas fueron rendimiento de semillas, germinación y supervivencia de plántulas. Se encontraron 73000 semillas viables y 3\% de impurezas por cada kilogramo de semilla recolectado. Las semillas tratadas con ácido sulfúrico fueron las que presentaron un mejor porcentaje de germinación y supervivencia (80 y 75.56\%); seguida por las tratadas con agua a $80^{\circ} \mathrm{C}(75.56$ y $73.34 \%)$. La escarificación de semillas de leguminosas debe ser un procedimiento imprescindible, mismo que debe hacerse con un ácido sulfúrico concentrado por cuanto se encontraron los mejores resultados en germinación de semillas y supervivencia de plántulas

Palabras claves: Escarificación, Latencia, Germinación, Leguminosa, Siratro

\section{Introducción.}

Los pastos cultivados en regiones con clima cálido a menudo presentan deficiencias en su contenido energético y proteico, el problema se agudiza aún más porque las pasturas presentan baja digestibilidad, lo cual hace que los engordes se prolonguen y la producción láctea sea limitada.

La tendencia mundial es la formación de bancos de proteína para poder suplir los requerimientos de los animales, para el efecto se utilizan leguminosas forrajeras y arbóreas que son fuente proteica. Al momento de establecer una pradera con leguminosas forrajeras se presenta un problema recurrente, conocido como latencia de la semilla. La latencia es una protección natural que asegura la supervivencia de la semilla y la especie en condiciones poco favorables para el desarrollo de las plántulas (Sanabria et al., 2011, González et al., 2012).

El efecto de latencia tiene un denominador común que son los inhibidores de crecimiento, éstos se encuentran en niveles altos y provocan un bloqueo de sustancias estimulantes, además las semillas presentan una dura cutícula que la impermeabiliza del agua también impide del suministro de oxígeno (Sánchez et al., 2007; Doria, 2010).

La aplicación de varias técnicas pregerminativas han demostrado ser efectivas para atenuar la dura corteza que rodean las semillas y acelerar e incrementar el proceso germinativo 
(Fariñas et al., 1997). Las técnicas de escarificación térmica, físicas y químicas son de mucha importancia al momento de incrementar la germinación, pese a eso, las leguminosas son de especies variadas y no suelen responder de la misma forma luego de ser expuestas a un método específico, el resultado está muy ligado a variables muy notorias como origen, época de cosecha, tiempo y tipo de almacenamiento (Sánchez et al., 1999, Reino et al., 2011).

Sin embargo, no todas las leguminosas responden de la misma manera ante la aplicación de sendas técnicas, el trabajo presente, estudia el comportamiento de las semillas de Siratro (Macroptilium atropurpureum) sometidas a varios tipos de escarificación y germinadas bajos las condiciones del trópico ecuatoriano.

\section{Materiales y Métodos}

\section{Localización y duración del experimento}

La presente investigación se llevó a cabo en las parcelas del hato bovino ubicado en la unidad de docencia, investigación y vinculación pastos y forraje de la Escuela Superior Politécnica Agropecuaria de Manabí (ESPAM). Ubicada en el sitio El Limón, parroquia Pedro Ángel Giler, cantón Tosagua, provincia de Manabí; a 15 msnm. El ensayo tuvo una duración de 120 días.

\section{Material vegetal}

Se recolectaron semillas de siratro (Macroptilium atropurpureum) que crece en las praderas destinadas para el pastoreo de la ganadería de doble propósito perteneciente a la carrera de medicina veterinaria de la ESPAM. Las semillas fueron deshidratadas al sol, para posteriormente proceder al contero de simillas y determinar el porcentaje de impurezas presentes la muestra.

\section{Tratamientos}

Tabla 1. Análisis de la varianza (ADEVA)

\begin{tabular}{lccc}
\hline Fuente de Variación & Fórmula & Cálculo & G.L \\
\hline Total & $\left(\mathrm{t}^{\star} \mathrm{r}\right)-1$ & $\left(15^{\star} 4\right)-1$ & 59 \\
Tratamientos & $(\mathrm{t}-1)$ & $(4-1)$ & 3 \\
Error Experimental & $\mathrm{t}(\mathrm{r}-1)$ & $3(6-1)$ & 56 \\
\hline
\end{tabular}

Para llevar a cabo el ensayo se propusieron cuatro tratamientos y quince repeticiones cada uno: T0 (semillas sin tratar), T1 (inmersión en ácido sulfúrico al 96\%, durante tres minutos), T2 (inmersión en agua a $80{ }^{\circ} \mathrm{C}$ durante cinco minutos) y T3 (remojo en agua potable por 24 horas). 


\section{Diseño experimental}

En la investigación se aplicó un Diseño Completamente Aleatorizado (DCA) con cuatro tratamientos y 15 repeticiones y la prueba de Tukey al 5\% para la comparación de medias, para procesar los datos se empleó el programa estadístico libre Infostat (2017), se utilizó el siguiente modelo estadístico:

$$
Y_{i j}=\mu+\mathrm{t}_{i}+€_{i j}
$$

$\boldsymbol{Y}_{i j}=$ observación del i-ésimo tratamiento

$\boldsymbol{\mu}=$ media general de la población

$\mathbf{t}_{i}=$ efecto del i-ésimo tratamiento

$\epsilon_{i j}=$ error atribuible a la medición $Y i j$.

\section{Unidades experimentales}

En esta investigación se utilizaron un total de 60 unidades experimentales, las unidades observacionales bajo estudio fueron tres semillas por unidad experimental las cuales se distribuyeron aleatoriamente en cuatro tratamientos y 15 repeticiones cada una, obteniendo 45 semillas por tratamiento.

Tabla 2. Esquema del experimento

\begin{tabular}{ccccc}
\hline Tratamiento & Código & $\begin{array}{c}\text { Tamaño Unidad } \\
\text { Experimental }\end{array}$ & Repeticiones & Total \\
\hline Testigo & T0 & 3 & 15 & 45 \\
Ac. Sulfúrico & T1 & 3 & 15 & 45 \\
Agua $80^{\circ} \mathrm{C}$ & T2 & 3 & 15 & 45 \\
Remojadas & T3 & 3 & 15 & 45 \\
\hline
\end{tabular}

\section{Factores en estudio}

Variable independiente: Método de escarificación

Variables dependientes: Rendimiento de semilla, germinación de semillas, supervivencia de plántulas. 


\section{Resultados y Discusión}

\section{Rendimiento de semillas y porcentaje de impurezas (100g)}

Tabla 3. Rendimiento de semillas $/ 100 \mathrm{~g}$

\begin{tabular}{cccc}
\hline Peso $(\mathrm{g})$ & Impureza $(\%)$ & Semilla limpia $(\%)$ & Semillas Viables $(\#)$ \\
\hline 100 & 3 & 97 & 7300 \\
\hline
\end{tabular}

En la Tabla 3 se aprecia que el número de semillas viables por cada $100 \mathrm{~g}$ es de 7300 , mientras que la presencia de impurezas fue de 3\%; valores similares a los reportados por Pérez (2010), quien en su estudio da cuenta de la existencia de un total de 80000 semillas por $\mathrm{kg}$; además obtuvo una pureza del 97.5\%; datos muy similares a los encontrados en la presente investigación.

\section{Germinación semanal}

En la Tabla 4 se observan los porcentajes de germinación Macroptilium atropurpureum, en la primera semana se notan diferencias significativas, las semillas tratadas con agua hervida y ácido sulfúrico presentan los mejores porcentajes de germinación $60.01( \pm 7.34 \%)$ y 46. $67( \pm 7.34 \%)$ respectivamente.

Tabla 4. Germinación de semillas de Siratro (\%)

\begin{tabular}{|c|c|c|c|c|c|c|}
\hline \multirow{3}{*}{ Tratamientos } & \multicolumn{6}{|c|}{ Porcentaje de Germinación } \\
\hline & \multicolumn{2}{|c|}{7 días } & \multicolumn{2}{|c|}{14 días } & \multicolumn{2}{|c|}{21 días } \\
\hline & \multicolumn{2}{|c|}{ * } & \multicolumn{2}{|r|}{$* *$} & \multicolumn{2}{|c|}{$\star *$} \\
\hline Testigo & 31,1 & $b$ & 44,45 & $\mathrm{~b}$ & 47,67 & $\mathrm{~b}$ \\
\hline Remojado & 28,88 & $b$ & 33,33 & $\mathrm{~b}$ & 33,33 & $b$ \\
\hline Agua caliente & 60,01 & a & 73,34 & a & 75,56 & a \\
\hline Ácido Sulfúrico & 46,67 & $a b$ & 80 & a & 80 & a \\
\hline $\mathrm{EE}$ & 7,34 & & 7,4 & & 7,47 & \\
\hline $\mathrm{p}$-valor & 0,0127 & & 0,0001 & & 0,0001 & \\
\hline
\end{tabular}

Promedio con letras distintas en la columna, difieren significativamente según la prueba de tukey al $5 \%$ de probabilidad.

n.s. No significativo.

* Diferencia significativa al $5 \%$

** Diferencia altamente significativa al $1 \%$.

E.E. Error estándar

En la segunda semana las diferencias que se observan son altamente significativas en las semillas tratadas con agua hervida y ácido sulfúrico los cuales presentan porcentajes de germinación de $73.34( \pm 7.4 \%)$ y $80( \pm 7.4 \%)$; en la tercera y última semana se aprecia diferencias altamente significativas en las semillas tratadas con agua hervida y ácido 
sulfúrico que presentan porcentajes de germinación de $75.56( \pm 7.47 \%)$ y $80( \pm 7.47 \%)$; valores que difieren a los reportados por Reino et al., (2011), quienes prueban escarificación de semillas de Centrosema Pubescens en el cual los valores de germinación con agua a $80^{\circ} \mathrm{C}$ es de $7 \%$, ácido sulfúrico 55 y el testigo 15. De igual forma el C. pubescens tratado con escarificación acida presentó una germinación de 72\% (Muñoz et al., 2009)

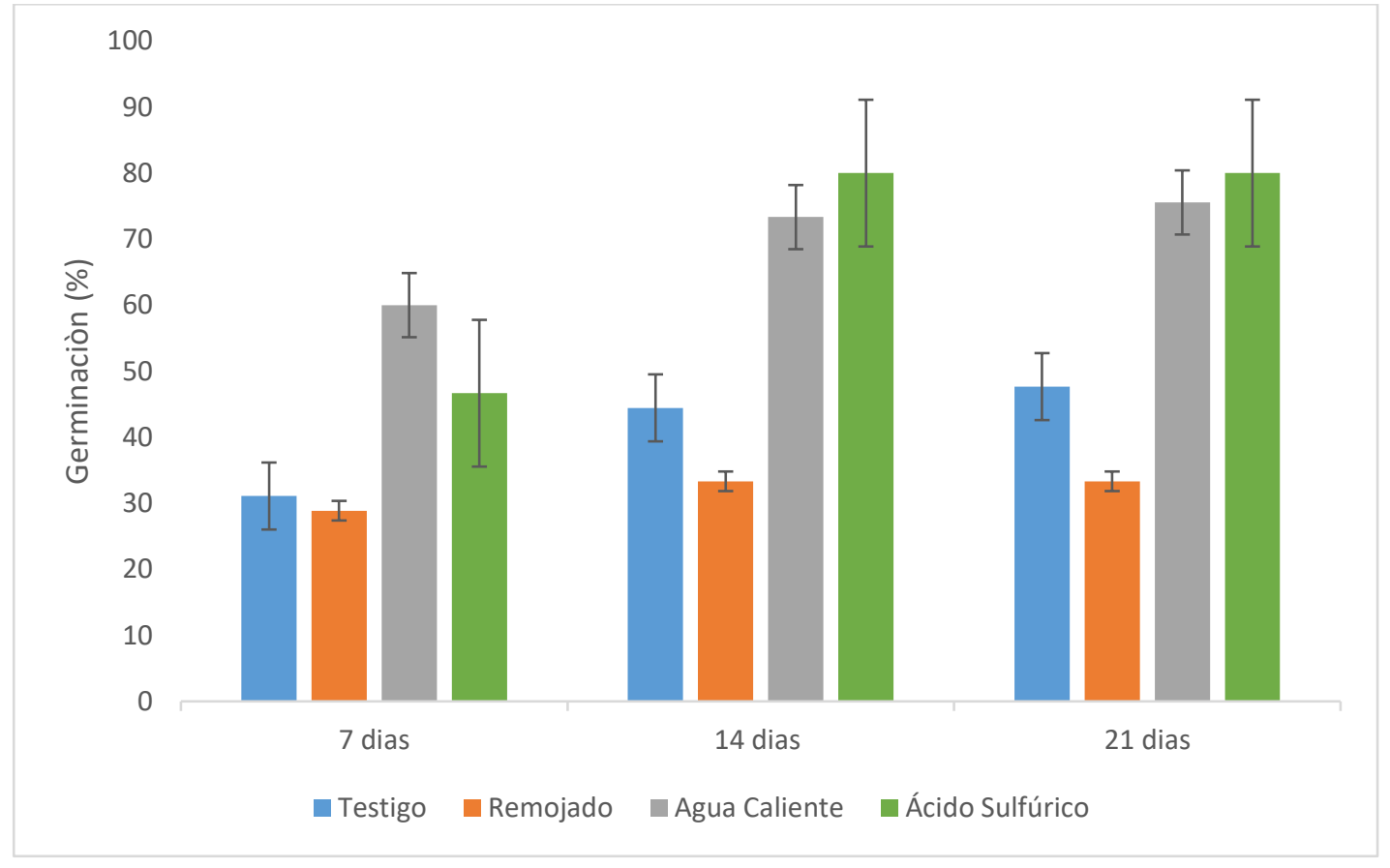

Gráfico 1. Semillas de Siratro germinadas luego de 21 días.

\section{Supervivencia de plántulas}

En el cuadro 4.3 se observan los datos de supervivencia Macroptilium atropurpureum, en la primera semana se notan diferencias significativas, las semillas tratadas con agua hervida y ácido sulfúrico presentan los mejores porcentajes de supervivencia de sus plántulas 60.01 $( \pm 7.34 \%)$ y $46.67( \pm 7.34 \%)$, similares resultados a los alcanzados por (González y Mendoza, 2009) quienes incrementaron germinación y viabilidad de la Leucaena leucocephala tratada con agua caliente a temperatura de $80{ }^{\circ} \mathrm{C}$.

En la segunda semana las diferencias que se observan son altamente significativas en las semillas tratadas con agua hervida y ácido sulfúrico los cuales presentan porcentajes de supervivencia de $71.12( \pm 6.77 \%)$ y $80( \pm 6.77 \%)$; en la tercera y última semana se aprecia diferencias altamente significativas en las semillas tratadas con agua hervida y ácido sulfúrico que presentan porcentajes de supervivencia de $73.34( \pm 6.94 \%)$ y $75.56( \pm 6.94 \%)$ respectivamente; valores que difieren a los reportados por Reino et al., (2011), quienes en su 
estudio presentan valores de supervivencia en semillas de Centrosema pubescens con agua a $80^{\circ} \mathrm{C}$ de 86 , ácido sulfúrico de 10 y el testigo de $55 \%$.

Tabla 5. Supervivencia de semillas de siratro (\%)

\begin{tabular}{|c|c|c|c|}
\hline \multirow{3}{*}{ Tratamientos } & \multicolumn{3}{|c|}{ Porcentaje de Supervivencia } \\
\hline & 7 días & 14 días & 21 días \\
\hline & * & ** & $\star \star *$ \\
\hline Testigo & $31,1 \quad b$ & $33,33 \mathrm{~b}$ & $28,89 b$ \\
\hline Remojado & 28,88 b & $22,21 \quad b$ & $22,21 b$ \\
\hline Agua caliente & 60,01 a & 71,12 a & 73,34 a \\
\hline Ácido Sulfúrico & $46,67 a b$ & $80 \mathrm{a}$ & 75,56 a \\
\hline EE & 7,34 & 6,77 & 6,94 \\
\hline p-valor & 0,0127 & 0,0001 & 0,0001 \\
\hline
\end{tabular}

Promedio con letras distintas en la columna, difieren significativamente según la prueba de tukey al $5 \%$ de probabilidad.

n.s. No significativo.

* Diferencia significativa al $5 \%$

** Diferencia altamente significativa al $1 \%$.

E.E. Error estándar

\section{Conclusión}

- El siratro (Macroptilium atropurpureum) en el trópico ecuatoriano produce 73000 semillas viables por Kilogramo cosechado y un contenido de impurezas de $3 \%$. El método de escarificación más adecuado para romper la latencia en las semillas fue la inmersión en ácido sulfúrico concentrado por tres minutos, las semillas presentaron mejor germinación y mayor supervivencia de plántulas, en comparación al resto de tratamientos.

\section{Referencias bibliográficas.}

Doria, J. 2010. Generalidades sobre las semillas: su producción, conservación y almacenamiento. Cultivos tropicales. 31(1):74-85.

Fariñas, J., Sanabria, V. \& Silva, R. 1997. Escarificación química de semillas de tres especies de Centrosema para sabanas bien drenadas. Zootecnia Tropical 15(2):221-237

González, Y. \& Mendoza, F. 2008. Efecto del agua caliente en la germinación de las semillas de Leucaena leucocephala cv. Perú. Pastos y Forrajes. 31(1):41-52

González, Y., Reino, J., Sánchez, J. \& Machado, R. 2012. Efecto del almacenamiento al ambiente en semillas de Leucaena leucocephala c sometidas a hidratación parcial. Pastos y Forrajes. 35(4):393-400 
Muñoz, B., Sánchez, J., Montejo, L., González, Y. \& Reino, J. 2009. Valoración germinativa de 20 accesiones de leguminosas almacenadas en condiciones desfavorables. Pastos y Forrajes. 32(3):200-212

Pérez, J. 2010. Establecimiento y manejo de bancos de proteína. Secretaria de Agricultura, Ganadería, Desarrollo Rural Pesca y Alimentación. Boletín Informativo. 2da Edición. Texcoco. México. Pág. 8.

Reino, J., Sánchez, A., Muñoz, B., González, Y. \& Montejo, L. 2011. Efecto combinado de la escarificación y la temperatura en la germinación de semillas de leguminosas herbáceas.

Sanabria, D., Silva, R., Oliveros, M. \& Barrios R. (2001). Escarificación química y térmica de semillas subterráneas de Centrosema rotundifolium. Bioagro. 13(3):117-124

Sánchez, G., Osorio, E., Álvarez, J., Marín, J., Sánchez, A \& Gil, O. 2007. Adaptación y producción de gramíneas y leguminosas forrajeras en el departamento de Antioquia, Colombia. Pasturas tropicales. 11(3):8-15

Sánchez, J., Calvo., E., Muñoz, B. \& Orta, R. 1999. Comparación de dos técnicas de acondicionamiento de semillas y sus efectos en la conducta germinativa del tomate, pimiento y pepino. Cultivos tropicales. 20(4):51-56 


\section{PARA CITAR EL ARTÍCULO INDEXADO.}

Oñate Mancero, F. J., Bravo Calle, O., Vaca Zambrano, E., \& Toapanta Santacruz, S. (2019). Semillas de siratro (Macroptilium atropurpureum) sometidas a escarificación química y térmica. Ciencia Digital, 3(3.1), 167-175. https://doi.org/10.33262/cienciadigital.v3i3.1.683

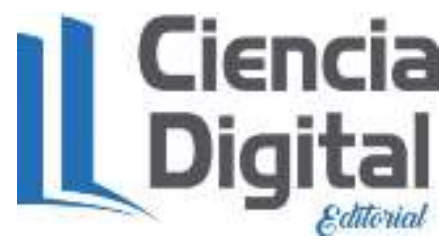

El artículo que se publica es de exclusiva responsabilidad de los autores y no necesariamente reflejan el pensamiento de la Revista Ciencia Digital.

El artículo queda en propiedad de la revista y, por tanto, su publicación parcial y/o total en otro medio tiene que ser autorizado por el director de la Revista Ciencia Digital.
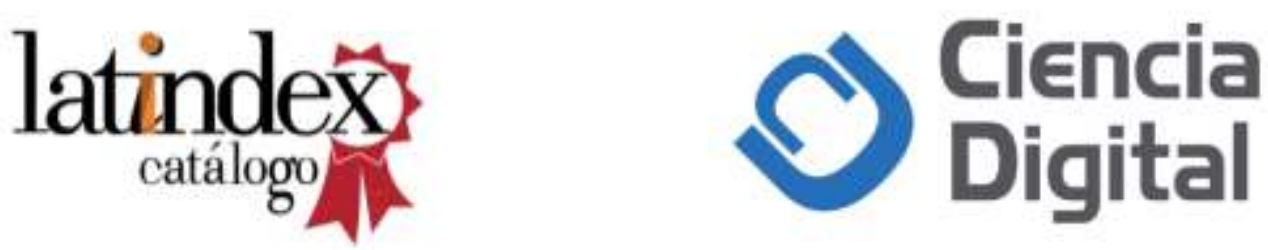